\title{
A department of social and preventive medicine in a district general hospital
}

\author{
W. J. MCQUiLlan \\ M.B., D.P.H., D.C.H. \\ County Medical Officer of Health for \\ Northamptonshire
}

\section{Summary}

The Bonham-Carter Report on the Functions of the District General Hospital favoured the idea of locating a department or office of the local health authority at the district general hospital, in order to help in achieving functional integration of the hospital and community health services.

This paper describes the establishment and development of such a department in a district general hospital, outlines its functions and describes some of the projects undertaken.

\section{Introduction}

The lack of co-operation between hospital and community services, examples of which have been given in a number of reports (Nuffield Provincial Hospitals Trust, 1962; Cartwright, 1964; Hockey, $1966,1968)$ has been attributed to the historical divisions between the hospital, general practitioner and local health authority services, which were perpetuated in the tripartite structure of the National Health Service. The efforts made by different authorities to overcome the difficulties created by this type of structure have been described (King's Fund, 1968), and the need for co-ordination and closer cooperation between the main branches of the Health Service, in order to ensure a more effective utilization of resources, has been frequently emphasized in recent years (Piercy Committee, 1956; Porritt Committee, 1962; National Health Service, 1968; Seebohm Committee, 1968).

The Report on the Functions of the District General Hospital (Bonham-Carter Committee, 1969) favoured the idea of locating a 'department or office of the local health authority at the district general hospital', as a method of helping to bring about the functional integration of the community health and hospital services. This was seen as desirable 'if there is to be real and continuing consultation between those responsible for the various services which interlock in so many ways'.

This paper describes the development of a local health authority Department of Social and Preven-

\author{
B. T. Williams \\ M.B., D.P.H., D.P.M. \\ Senior Medical Officer for Adult Health, \\ Northamptonshire
}

tive Medicine in a general hospital and outlines its functions.

\section{Development}

In 1962, when plans for the rebuilding of Kettering General Hospital were being prepared, a proposal to establish a Department of Social and Preventive Medicine at the hospital as a joint venture was accepted by the Oxford Regional Hospital Board and Northamptonshire County Council (Reid, 1962). The principal aim in setting up this Department was to assist in the planning of total care and after-care of hospital patients. To achieve this certain objectives were suggested, one of the most important being to improve communications between the local health authority and hospital staffs.

Accommodation was to be provided in two offices in the second phase of the new hospital development. The first phase was completed in 1965 and includes the Casualty Department and wards, the Outpatient, Physical Medicine and Medical Records Departments, and the Pharmacy. The second phase is scheduled to begin in 1970 . At a meeting of the Medical Advisory Committee at Kettering General Hospital in November 1965, it was suggested that the Department should be accommodated temporarily in a caravan modified to provide two offices, pending the completion of phase II of the hospital re-development. This suggestion was accepted by both authorities, and it was agreed that it should be established in the latter half of the year 1967/68.

Initially the Department was to be staffed by one clerk, with assistance from other staff as this became necessary. It was known that the amount of medical supervision which it would need to achieve its potential would be limited in the first year, due to staffing difficulties. Particular attention was therefore given to the appointment of the clerk, who, it was anticipated, would have to cope not only with the pressures inherent in the post but would also be likely to meet with a certain amount of resistance and possibly resentment from some of the hospital staff. 
In October 1967 a senior clerk was recruited from a responsible position in industry and, after an induction course which provided the opportunity of learning about the health and social services in the area, she took up duty in the Department in December 1967 in the caravan located near the Outpatient Department. The clerk met as many as possible of the key personnel in the hospital, in order to ensure that the functions of the Department were known to them and to gain their confidence. In September 1968 an additional senior medical officer was appointed to the staff of the County Health Department, whose duties included the supervision of the Department of Social and Preventive Medicine. In 1969 he was appointed Honorary Clinical Assistant in Social and Preventive Medicine to the hospital, and subsequently was invited to join the Medical Advisory Committee.

\section{Functions}

Of necessity the activities of the Department were limited in the initial stages of its development. All members of the local health authority staff and the senior staff in the hospital were informed of the aim in establishing it. In order to facilitate the achievement of its objectives, it was thought necessary to demonstrate that the Department could provide a useful service to the hospital. Although a considerable number of links between the hospital and domiciliary services already existed in this area, nevertheless the improvement of communications between the hospital and the local health authority and the provision of a common intelligence service were given priority.

\section{Improvement of communications}

The Department acts as a focal point to which requests for local health authority services originating from hospital staff are directed. For example, requests for the provision of home helps, medical loans or home nursing are received from medical social workers and ward sisters, and are then passed on by the departmental clerk to the appropriate person in the local health authority. In this way a saving in the time of hospital nursing and social work staff is effected, where previously it was dissipated in trying to contact the appropriate agencies in the community. In a recent report, the time spent on organizing such services was said to be a source of frustration to medical social workers, and a need to delegate clerical and other administrative tasks was expressed (Institute of Medical Social Workers, 1962). Requests for the assistance of health visitors, particularly for supervisory visits to diabetic patients and to the families of children who repeatedly fail to attend the paediatric outpatient clinics, are channelled through the Department. In addition, the Department receives the names of all children under the age of 5 years who are discharged from the hospital and passes them on to the health visitors, so that follow-up visits can be carried out where necessary.

The exchange of information is a two-way process between hospital and local health authority staff. The Department is a focal point through which information is channelled from the staff in the community concerning patients in hospital or attending outpatient'departments, whilst information about patients in hospital, attending outpatient departments or who have recently been discharged is passed on request to local health authority staff. This exchange of information is of importance in view of the fact that most of the local health authority's nursing, health visitor and midwifery staff are now attached to general practitioners.

The increasing use made of the Department by hospital staff is illustrated in Table 1 , from which it can be seen that the number of referrals during 1969 exceeds the number of referrals for the previous year.

\section{Intelligence service}

The need to plan hospital and domiciliary health services together, in order to ensure that the best use 'will be made of specialized and expensive hospital facilities', has been stressed (Bonham-Carter Committee, 1969). The Department of Social and Preventive Medicine can act not only as a bridge between the hospital and local health authority, but can also play an important part in the planning process by providing an intelligence and monitoring

TABLE 1. Referrals by hospital staff for community services

\begin{tabular}{cccccccc}
\hline Year & $\begin{array}{c}\text { Home } \\
\text { help }\end{array}$ & $\begin{array}{c}\text { Medical } \\
\text { loans and } \\
\text { nursing } \\
\text { aids }\end{array}$ & $\begin{array}{c}\text { Home } \\
\text { nurse }\end{array}$ & $\begin{array}{c}\text { Children } \\
\text { under 5 } \\
\text { discharged }\end{array}$ & $\begin{array}{c}\text { Paediatric } \\
\text { Clinic } \\
\text { defaulters }\end{array}$ & Other & Total \\
\hline 1968 & 98 & 74 & 15 & 549 & 51 & 24 & 811 \\
1969 & 174 & 174 & 55 & 824 & 143 & 63 & 1433 \\
\hline
\end{tabular}


service to staff working in these two branches of the Health Service, and in time to general practitioners also.

The following are some of the projects which have been undertaken by the Department. These have been of value not only because of the useful information acquired, but also because the co-operation needed to carry out the work helped to strengthen links between both authorities.

At a regional Medical Officers of Health Liaison Committee at Oxford in April 1967, attention was drawn to the increase in the number of admissions of children for accidental poisonings to hospitals in the Oxford region. As the number of admissions to Kettering General Hospital appeared to be higher than elsewhere in the region, an undertaking was given to investigate this problem. Preparatory work was carried out on this project before the Department of Social and Preventive Medicine was established, but subsequently the staff of the Department found that having access to the Medical Records Department of the hospital was invaluable as an aid to studying the problem. The trends in hospitalization of children for accidental poisoning and other accidents were observed and factors reflecting changes in referral policy on the part of general practitioners and parents were identified and taken into account when interpreting the apparently enormous increase in the number of admissions for accidental poisonings (Wigglesworth \& Williams, 1968)

A study of the use which is being made of the facilities available for cervical cytology was undertaken, and the origin of cervical smears processed in the hospital cytology laboratory has been observed. The extent to which women fail to take advantage of the cervical cytology service has been calculated and the effectiveness of the different methods employed to persuade women in the highest risk groups to undergo the smear test has been studied. In this context also, the collection of information for the follow-up of patients with positive cervical smears is undertaken on behalf of the Regional Hospital Board.

Continuity of care is important (Bonham-Carter Committee, 1969), and one of the main objectives of the Department from the beginning has been to ensure that as far as possible patients are discharged from hospital to planned domiciliary care. In order to assess the present situation and to obtain a baseline against which the effects of any change in procedure can be measured, the extent to which patients who report social problems are referred to the medical social workers while in hospital has been investigated and the findings are being discussed with the hospital staff.

The promotion of health education activities was one of the original objectives of the Department.
Health education displays are organized in the two general hospitals in the area and are undertaken by the County Health Department. Exhibits which are on display in the waiting areas of the outpatient departments at the hospitals are changed periodically. A survey was carried out at Kettering General Hospital to ascertain the extent to which members of the public perceive and understand the various displays, in the expectation that the information gained would help to increase the effectiveness of future displays (Wingfield \& Williams, 1969)

Recently some consultants have begun to request collaboration with the epidemiological aspects of their specialties. For example, in conjunction with a consultant physician a comparison is being made of the factors determining why some patients who subsequently died from ischaemic heart disease were admitted to hospital while an apparently similar group died at home, and a study of the relationship between errors of refraction in children and their blood groups is being mounted in co-operation with a consultant ophthalmologist.

It is known that the extent of notification of infectious disease is increased when the reporter has a personal interest in collecting the data (College of General Practitioners, 1963). The interest of the staff of the Department of Social and Preventive Medicine in the hospital may be expected, therefore, to lead to an increase in the proportion of cases of infectious diseases admitted to the hospital which are notified to the local health authority. In one instance a consultant physician noted an increase in the number of cases of benign lymphocytic meningitis admitted to the hospital in 1968 compared with previous years. The epidemiology of this outbreak was studied through the Department, which was in a position to co-ordinate the epidemiological investigations carried out by staff of the urban and rural district health authorities, from whose areas patients entered the hospital.

\section{Discussion}

Some of the original objectives have already been achieved by the Department of Social and Preventive Medicine. It has now been firmly established in the precincts of the district general hospital, and its services are being used to an increasing extent both by local health authority and hospital staff, reflecting an improved channel of communication between both staffs. Links have been forged with key departments in the hospital, in particular the departments of Social Work and Medical Records. The local health authority's medical officer has been accepted as a colleague by the medical staff of the hospital, as shown not only by the increasing use being made of his services but also by their invitation to him to join the Medical Advisory 
Committee and to present reports on the Department's work to the hospital's postgraduate study meetings.

However, the Department has had its share of teething troubles. The climate of present-day thinking in regard to the relationships between medical officers of health and social workers was reflected in the need to allay the fears of the hospital medical social workers, who felt that their positions were threatened with the establishment of this new Department. These fears were taken into account when the clerk was first being appointed, and candidates who appeared to be seeking a post involving social work, rather than clerical work, were not considered in the final choice. The resistance from certain sections of the hospital staff has gradually been overcome by personal contact and a full explanation of the functions of the Department and the role of its staff. As the name of the Department has also given rise to some misunderstanding, consideration is being given to finding a shorter and more appropriate title.

The reaction of the hospital medical staff to the Department was, with a few exceptions, understandably cautious. However, the appointment of the additional senior medical officer, almost a year after the inception of the Department, helped to clarify its role for some members of the medical staff.

The establishment of a resettlement clinic to help in the rehabilitation of disabled patients (Mair \& Reid, 1957; Warren, 1960), which was one of the original objectives, is now feasible. In addition, the definition of further objectives is possible. For example, it is hoped to identify the optimum time during hospitalization for arranging aftercare for patients with different needs. It is also proposed to determine whether all patients requiring home nursing care on discharge from hospital obtain the appropriate care promptly, and whether the involvement of a local health authority senior nursing officer in the work of the Department would contribute to this.

There are many such tasks which could be undertaken in the Department which would assist in planning health services in the area. An important first step is to establish base-line measurements of the way in which the health services are functioning, against which the effect of instituting changes can be evaluated. The staff of the Department, through familiarity with the working of the hospital and community services, are also in a position to ascertain unmet needs, and the information obtained could be of value to those participating in policy discussions and should be of assistance in determining priorities.

Requests for reprints should be sent to W. J. McQuillan, County Health Department, Guildhall Road, Northampton, NN1 1DX.

\section{References}

BONHAM-CARTER COMmitTeE (1969) Report of the Committee on the Functions of the District General Hospital. H.M.S.O., London.

CARTWRight, A. (1964) Human Relations and Hospital Care. Routledge \& Kegan Paul, London.

College of General Practitioners (1963) The records and statistical unit. Journal of the College of General Practitioners, 6, 217.

HoCKEY, L. (1966) Feeling the pulse: a survey of district nursing in six areas. Queen's Institute of District Nursing.

Hockey, L. (1968) Care in the balance: a study of collaboration between hospital and community services. Queen's Institute of District Nursing.

Institute of Medical Social Workers (1962) The first two years. Swale Press Ltd., London.

KING'S FUND (1968) Working together: a study of coordination and co-operation between general practitioner, public health and hospital services. King Edward's Hospital Fund for London.

MaIR, A. \& ReID, J.J.A. (1957) Resettlement in teaching hospitals: a practical exercise in social medicine. Scottish Medical Journal, 2, 467.

National Health Service (1968) The Administrative Structure of the Medical and Related Services in England and Wales. H.M.S.O., London.

Nuffield Provincial Hospitals TRust (1962) Further Studies in Hospital and Community. Oxford University Press.

PIERCY COMmittee (1956) Report of Committee of Enquiry on the Rehabilitation, Training and Ressettlement of Disabled Persons. Cmnd. 98. H.M.S.O., London.

PorRitr COMmitTeE (1962) Medical Services Review Committee, A Review of the Medical Services in Great Britain. Social Assay, London.

ReID, J.J.A. (1962) A ten year plan for the development of Northamptonshire's health services. Northants County Council.

Sеввонм Сомmittee (1968) Report of the Committee on Local Authority and Allied Personal Social Services. Cmnd. 3703. H.M.S.O., London.

WARREN, M.D. (1960) The hospital resettlement clinic and the community care of handicapped people. Medical Officer, 106, 69.

WigglesWORTH, R. \& Williams, B.T. (1968) Accidental poisoning in children (corr.). British Medical Journal, 4, 514 .

Wingfield, J.M. \& Williams, B.T. (1969) Public perceptiveness to a poster display in a hospital outpatient department. Health Education Journal, 28, 4. 234. 